FDM vào thực tiễn thì viêc kiểm soát và nâng cao chất lượng sản phẩm là vô cùng quan trọng. Nguyên vật liệu, thành phần trong công thức thuốc cần được lựa chọn cẩn thận. Một phần để đảm bảo chất lượng sản phẩm đầu ra. Măt khác, không kém phần quan trọng, giúp đảm bảo quá trình in được diễn ra thuận lợi và thông suốt. Song song với đó, các thông số in như nhiệt độ, tốc độ in, độ dày lớp in, góc nghiêng đường in, góc nghiêng vật in, độ lấp đầy, bề dày lớp vỏ... cũng cần được tối ưu hóa nhằm tăng tính khả thi và cải thiện chất lượng sản phẩm.

\section{TÀI LIẸU THAM KHẢO}

1. Zhang, J., et al. (2019). "Development and evaluation of pharmaceutical 3D printability for hot melt extruded cellulose-based filaments.". Journal of drug delivery science and technology, 52, 292.

2. Henry, S., et al. (2021). "Extrusion-based $3 D$ printing of oral solid dosage forms: Material requirements and equipment dependencies.". International journal of pharmaceutics, 598, 120361.
3. Cailleaux Sylvain, e.a. (2020). "Fused Deposition Modeling (FDM), the new asset for the production of tailored medicines." Journal of Controlled Release

4. Melocchi, A., et al. (2015). "3D printing by fused deposition modeling (FDM) of a swellable/erodible capsular device for oral pulsatile release of drugs.". Journal of Drug Delivery Science and Technology, 30, 360-367.

5. Solomon, I.J., P. Sevvel, and J. Gunasekaran. (2021). "A review on the various processing parameters in FDM." Materials Today: Proceedings, 37, 509-514.

6. Zhang, J., et al. (2020). "Structure-function correlation and personalized 3D printed tablets using a quality by design (QbD) approach.". International Journal of Pharmaceutics 590, 119945.

7. Vo, A.Q., et al (2020). "Hot melt extrusion paired fused deposition modeling 3D printing to develop hydroxypropyl cellulose based floating tablets of cinnarizine." Carbohydrate Polymers, 246

8. Mitsouras, D., and Peter C. Liacouras. (2017). 3D printing technologies. In $3 \mathrm{D}$ printing in medicine, 5-22.

\title{
ĐẶC ĐIỂM DI ỨNG VÀ KẾT QUẢ NHẬN DANG THUỐC CHỐNG LAO HÀNG 1 GÂY DI ỨNG TRÊN DA BẰNG TEST KÍCH THÍCH
}

\section{TÓM TẮT}

Tổng quan: Cần phát hiện sớm các triệu chứng của dị ứng và có biện pháp xử lý kịp thời để tối ưu hóa vieêc điều trị thuốc chống lao. Mục tiêu: Mô tả đặc điểm di ứng và kết quả nhân dạng thuốc chống lao hàng 1 gây dị ứng trên da bằng test kích thích tại bệnh viện Phổi Trung Ương. Phương pháp: nghiển cứu mô tả cắt ngang 86 bệnh nhân lao phổi có chẩn đoán dị ứng thuốc lao, nhập viện tại khoa Lao hô hấp bệnh viện Phổi Trung ương từ tháng 8/2018 đển tháng 6/2019. Loại trừ bệnh nhân sốc phản vệ, dị ứng nặng, hội chứng SJS, Lyell, DRESS; có tình trạng co thắt đường thở không kiêm soát (FEV1<70\%). Kêt quả: 48 bệnh nhân $(55,8 \%)$ biểu hiện mày đay, ban chấm; 85 bệnh nhân $(98,8 \%)$ biểu hiện ngứa. Tổn thương da: $55 \%$ mức độ $2,39 \%$ mức độ 3 và $6 \%$ mức độ 4. Điêu trị trước khi test kích thích: số ngày điều trị trung bình 4,3 ngày (1-16 ngày), $33,7 \%$ số trường hợp phải sử dụng cả thuốc kháng histamin và corticoid. Có 81 bênh nhân đước test kích thích với tổng số 346 lần testi, trong đó có 80 lần test kích thích cho kết quả dương tính. Thuốc có tỉ lệ dị ứng từ cao

\footnotetext{
${ }^{1}$ Bệnh viện Phổi Trung ương

${ }^{2}$ Đại học Y Hà Nọi

Chịu trách nhiệm chính: Hoàng Tuấn

Email: hoantuan@hmu.edu.vn

Ngày nhận bài: 19.4.2021

Ngày phản biện khoa học: 28.5.2021

Ngày duyệt bài: 16.6.2021
}

, Nguyễn Kim Cương1,2, Nguyễn Mạnh Thế

đến thấp lần lượt RIF, PZA, EMB, INH. Có 54 bệnh nhân dị ứng với chỉ 1 loại thuốc, 13 bệnh nhân dị ứng với 2 loại thuốc, không có trường hợp nào di ứng với từ 3 thuốc trở lên. Đa số bệnh nhẩn test kích thích dương tính vào ngày thứ 2 hoặc thứ 3 . Kết luận: Phác đồ điều trị bệnh lao gồm nhiều thuốc phối hợp do đó khi xảy ra phản ứng di ứng rất khó khăn trong chẩn đoán thuốc gây ra phản ứng. Tuy nhiên khi thực hiên test kích thích, lần lượt từng thuốc được tiến hành do đó có thể xác định nguyên nhân gây dị ứng môt cách chính xác

Tư khóa: dị ứng thuốc lao, ADR, test kích thích

\section{SUMMARY}

\section{ALLERGIC CHARACTERISTICS AND RESULTS OF PROVOCATION TEST IN PATIENTS WITH ANTI-TUBERCULOSIS DRUG ALLERGY}

Background: Early detection of hypersensitivity reactions and appropriate management should be taken to optimize the treatment of tuberculosis. Objective: Description of hypersensitivity reactions from first-line antituberculosis drugs and results of drug provocation test at National Lung Hospital. Methods: Cross-sectional study of 86 pulmonary tuberculosis patients with signs and symtomps of hypersensitivity reactions, who were hospitalized and treated in the Department of Respiratory Tuberculosis at National Lung Hospital from August 2018 to June 2019. Excluded from the study were patients with anaphylaxis, severe allergy, SJS, Lyell syndrome, 
DRESS and who have uncontrolled obstructive airway (FEV1 <70\%). Results: 48 patients $(55.8 \%)$ were detected urticaria, rash; 85 patients $(98.8 \%)$ were detected pruritus. Cutaneous lesions: $55 \%$ at level 2 , $39 \%$ at level 3 and $6 \%$ at level 4 . Symptoms treatment before drugs provocation test: average duration of treatment is 4.3 days ( $1-16$ days), $33,7 \%$ cases must be taken both antihistamines and corticosteroids. 81 patients were applied drugs provocation test with a total of 346 tests, of which 80 had a positive test. Prevalence of allergic drugs from high to low respectively: RIF, PZA, EMB, INH. 54 patients were allergic to only 1 drug, 13 patients were allergic to 2 drugs, nobody was allergic to 3 drugs or more. Most patients had positive provocation test on the $2^{\text {nd }}$ or $3^{\text {rd }}$ day of protocol. Conclusion: The TB treatment regimen consists of a combination of drugs, so when an allergic reaction occurs it is very difficult to diagnose the drug that causes the reaction. However, when performing drug provocation test, it can identify correctly the cause of allergy.

\section{I. ĐẶT VẤN ĐỀ}

Dị ứng thuốc là một trong những tác dụng không mong muốn- phản ứng bất lợi do thuốc (ADR). Biểu hiện dị ứng thuốc đa dạng, tổn thương nhiều cớ quan và khác nhau về thời gian và mức độ trầm trọng của bệnh. Nghiên cứu trên thế giới cũ̃ng như ở Việt nam, phản ứng quá mẫn do thuốc điều trị lao dẫn tới ngừng điều trị hoặc thay đổi liệu pháp điều trị vào khoảng 4 - $5 \%$ BN điều trị lao. Dị ứng thuốc chống lao biểu hiện ở nhiều mức độ, có thể tự ổn định, cho tới những trường hợp nặng như Shock phản vệ, các hội chứng Lyell, Steven - Johnson, hoặc gây viêm gan cấp, hoại tử tế bào gan, góp phần tăng nguy cơ kháng thuốc chống lao trong cộng đồng. Một số ít nghiên cứu trên thế giới đã đề cập đến vấn đề nhận dạng thuốc gây dị ứng và giảm mẫn cảm, tuy nhiên tại Việt Nam thì hầu như chưa có nghiên cứu cụ thể. Vì vậy chúng tôi tiến hành nghiên cứu này với mục tiêu: Mô tả đặc điểm dị ứng và kết quả nhận dạng thuốc chống lao hàng 1 gây dị ứng trên da bằng test kích thích.

\section{II. ĐỐI TƯỢNG VÀ PHƯƠNG PHÁP NGHIÊN CỨU}

Nghiên cứu cắt ngang 86 bênh nhân được chẩn đoán lao phổi tại bệnh viện Phổi Trung ương từ tháng 8 năm 2018 đến tháng 6 năm 2019, có phản ứng dị ứng trên da. Loại trừ bệnh nhân sốc phản vệ, dị ứng nặng, hội chứng SJS, Lyell, DRESS; có tình trạng co thắt đường thở không kiểm soát $(F E V 1<70 \%)$. Bệnh nhân dị ứng thuốc lao được ghi nhận các triệu chứng dị ứng, phân loại theo mức độ (Bảng 1).

Sau khi điều trị hết các phản ứng dị ứng, tiến hành nhận dạng thuốc gây dị ứng bằng test kích thích (Bảng 2). Test kích thích được chỉ định trong trường hợp: Loại trừ phản ứng quá mẫn ở bênh nhân không có tiền sử dị ứng thuốc lao và có triệu chứng dị ứng nhưng không đặc hiệu; Thiết lập chẩn đoán dị ứng thuốc lao ở bệnh nhân có bệnh cảnh dị ứng thuốc, nhưng các xét nghiệm khác về dị ứng lại âm tính, hoặc không thể đưa ra kết luận, hoặc không sẵn có trong điều kiện của cơ sở thực hành. Chống chỉ định thực hiện test kích thích với phụ nữ có thai, bềnh nhân có tiền sử dị ứng nặng trước đó: sốc phản vệ, hội chứng SJS, Lyell, DRESS. Test kích thích được cho là dương tính khi: Tổn thương da dạng mày đay (sẩn phù màu hồng đường kính tử vài $\mathrm{mm}$ đến vài $\mathrm{cm}$, ranh giới khá rõ, hình tròn hoăc hình bầu dục), ngứa nhiều kèm theo các dấu hiệu khác: đau bụng, khó thở, đau khớp, chóng mă̆t, buồn nôn, sốt cao, giá tri men gan tăng > 2 lần giá trị bình thường; Phù hợp về thời gian xảy ra phản ứng dị ứng. Nếu test kích thích dương tính, điều trị khỏi tổn thương dị ứng trước khi thực hiên với thuốc tiếp theo bằng các thuốc kháng histamin, corticoid, giãn phế quản, adrenalin... Test kích thích được cho là âm tính khi không có các biểu hiện ngoài da. Thực hiện tiếp với từng thuốc còn lại theo thứ tự (bảng 2), đồng thời tiếp tục sử dụng thuốc không gây dị ứng ở liều điều trị.S

\section{Bảng 1: Phân loai các mức độ dị ứng trên da}

\begin{tabular}{|c|c|c|c|c|}
\hline & Mức đồ 1 & Mức độ 2 & Mức độ 3 & Mức độ 4 \\
\hline $\begin{array}{l}\text { Phản } \\
\text { ứng } \\
\text { của } \\
\text { da- nổi } \\
\text { ban }\end{array}$ & $\begin{array}{c}\text { Ban chấm khu } \\
\text { trú }\end{array}$ & $\begin{array}{l}\text { Ban chấm, nốt sẩn } \\
\text { rải rác hoặc ban sởi }\end{array}$ & $\begin{array}{l}\text { Ban chấm, nốt sấn rải } \\
\text { rác hoặc ban dạng sởi } \\
\text { với các nốt phỏng nước } \\
\text { hoăc tổn thương loét bề } \\
\text { mặt niêm mạc giới hạn } \\
\text { tai môt vi trí }\end{array}$ & $\begin{array}{l}\text { Các tổn thương lan } \\
\text { rộng hoặc toàn thân } \\
\text { hoặc hội chứng } \\
\text { Stevens-johnson, } \\
\text { hoặc hội chứng Lyell }\end{array}$ \\
\hline $\begin{array}{l}\text { Phản } \\
\text { ứng dị } \\
\text { ứng } \\
\text { toàn } \\
\text { thân }\end{array}$ & $\begin{array}{l}\text { Nối mày đay } \\
\text { khu trú nhưng } \\
\text { không cần chỉ } \\
\text { định can thiệp y } \\
\text { khoa }\end{array}$ & $\begin{array}{l}\text { Nối mày đay khu } \\
\text { trú nhưng cân chỉ } \\
\text { định can thiệp y } \\
\text { khoa hoặc phù } \\
\text { mạch khồng cần }\end{array}$ & $\begin{array}{c}\text { Nối mày đay toàn thân } \\
\text { hoăc phù maach cần chỉ } \\
\text { định can thiệp y khoa } \\
\text { hoặc bị co thắt phế } \\
\text { quản nhẹ }\end{array}$ & $\begin{array}{c}\text { Phản về hoắc co thắt } \\
\text { phế quản nặng đe } \\
\text { dọa tính mạng hoăc } \\
\text { phù thanh quản, tổn } \\
\text { thương viêm câuu }\end{array}$ \\
\hline
\end{tabular}


TẠP CHÍ Y HỌC VIẸTT NAM TẬP 503 - THÁNG 6 - SỐ 2 - 2021

\begin{tabular}{|c|c|c|c|c|}
\hline $\begin{array}{l}\text { cấp } \\
\text { tính }\end{array}$ & & $\begin{array}{c}\text { chỉ định can thiệp y } \\
\text { khoa }\end{array}$ & & $\begin{array}{l}\text { thận/ hội chứng thận } \\
\text { hư, viêm mạch lupus }\end{array}$ \\
\hline Ngứa & $\begin{array}{l}\text { Ngứa không gây } \\
\text { hoặc ít gây ảnh } \\
\text { hưởng tới các } \\
\text { hoạt động chức } \\
\text { năng và xã hội } \\
\text { thông thường }\end{array}$ & $\begin{array}{l}\text { Ngứa gây ra hạn } \\
\text { chế hoạt động của } \\
\text { chi hoặc gây ảnh } \\
\text { hưởng nhiều hơn } \\
\text { đến các hoạt động } \\
\text { chức năng và xã } \\
\text { hội thông thương }\end{array}$ & $\begin{array}{l}\text { Ngứa gây mất khả năng } \\
\text { thực hiện các hoạt động } \\
\text { chức năng và xã hội } \\
\text { thông thường }\end{array}$ & Không áp dụng \\
\hline Sốt & $37,7-38,6^{\circ} \mathrm{C}$ & $38,8-39,3^{\circ} \mathrm{C}$ & $39,4-40,5^{\circ} \mathrm{C}$ & $>40,5^{\circ} \mathrm{C}$ \\
\hline
\end{tabular}

Bảng 2: Hướng dẫn thực hiện nhận dạng thuốc gây dị ứng bằng test kích thích

\begin{tabular}{|c|c|c|c|c|}
\hline Thứ tự thuốc & Liêuu 1 (ngày 1) & Liêuu 2 (ngày 2) & Liêuu 3 (ngày 3 ) & Liều 4(ngày 4) \\
\hline EMB & $100 \mathrm{mg}$ & $400 \mathrm{mg}$ & $800 \mathrm{mg}-1200 \mathrm{mg}$ & $800-1200 \mathrm{mg}$ \\
\hline INH & $50 \mathrm{mg}$ & $100 \mathrm{mg}$ & $300 \mathrm{mg}$ & $300 \mathrm{mg}$ \\
\hline RIF & $75 \mathrm{mg}$ & $150 \mathrm{mg}$ & $300-450 \mathrm{mg}$ & $450-600 \mathrm{mg}$ \\
\hline PZA & $250 \mathrm{mg}$ & $1000 \mathrm{~g}$ & $1500-2000 \mathrm{mg}$ & $1500-2000 \mathrm{mg}$ \\
\hline \multicolumn{5}{|c|}{ Test kích thích với 4 đơn chất âm tính tiến hành test kích thích với rhz,rh } \\
\hline RHZ & $312,5 \mathrm{mg}$ & $625 \mathrm{mg}$ & $1875-25($ & $1875-2500 \mathrm{mg}$ \\
\hline $\mathrm{RH}$ & $125 \mathrm{mg}$ & $250 \mathrm{mg}$ & $750-1000 \mathrm{mg}$ & $750-1000 \mathrm{mg}$ \\
\hline
\end{tabular}

Thu thập số liệu theo mầu phiếu nghiên cứu, xử lí theo phương pháp thống kê y học, sử dụng phần mềm SPSS 21.0. Sử dụng test $\chi^{2}$ so sánh các tỉ lệ, sự khác nhau có ý nghĩa thống kê khi $p<0,05$.

III. KẾT QUẢ NGHIÊN CỨU

1. Đặc điểm dị ứng trên da

Bảng 3: Đặc điểm dị ứng trên da và hướng xử trí

\begin{tabular}{|c|c|c|}
\hline 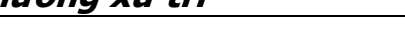 & $\mathbf{n}$ & $\%$ \\
\hline Giới: & 54 & 62,8 \\
\hline Nứ & 32 & 37,2 \\
\hline \multicolumn{3}{|l|}{ Biếu hiên trên da } \\
\hline Mày đay, ban chấm & 48 & 55,8 \\
\hline Ngứa & 85 & 98,8 \\
\hline
\end{tabular}

Thời gian xuất hiện triệu chứng sau khi dùng thuốc lao

\begin{tabular}{|c|c|c|}
\hline Cấp tính (0-1h) & 8 & 9 \\
\hline Bán cấp (1-24h) & 34 & 40 \\
\hline Muộn (sau 24h) & 44 & 51 \\
\hline Mức độ dị ứng \\
\hline Mức độ 2 & 47 & 55 \\
\hline Mức độ 3 & 33 & 39 \\
\hline
\end{tabular}

\begin{tabular}{|c|c|c|}
\hline Mức độ 4 & 5 & 6 \\
\hline \multicolumn{3}{|c|}{ Điêuu trị khi xuất hiện dị ứng } \\
\hline Kháng histamin & 38 & 44,2 \\
\hline Corticoid & 2 & 2,3 \\
\hline $\begin{array}{c}\text { Kháng histamin kết hợp } \\
\text { corticoid }\end{array}$ & 29 & 33,7 \\
\hline
\end{tabular}

Nhận xét: Trong 86 bệnh nhân, 48 bệnh nhân có biểu hiện mày đay, ban chấm chiếm tỉ lệ $55,8 \%$ và 85 bệnh nhân biểu hiện ngứa chiếm tỉ lệ $98,8 \%$. Tổn thương da mức độ 2 có 47 bệnh nhân chiếm tỉ lệ $55 \%$, mức độ 3 chiếm $39 \%$ và mức độ 4 chiếm tỉ lệ thấp nhất với 5 bệnh nhân (6\%). Không có bệnh nhân tổn thương da mức độ 1 . Số ngày điêu trị hết dị ứng trước khi test kích thích trung bình 4,3 ngày (1-16 ngày). Sử dụng kháng histamin chiếm tî lệ $44,2 \%$, kháng histamin kêt hợp corticoid chiếm tỉ lệ 33,7\%.

Bảng 4: Kêt quả test kích thích

\begin{tabular}{|c|c|c|c|c|}
\hline $\begin{array}{c}\text { Loai thuốc test } \\
\text { kích thích }\end{array}$ & $\begin{array}{c}\text { Test kích thích } \\
\text { dương tính }\end{array}$ & $\begin{array}{c}\text { Test kích } \\
\text { thích âm tính }\end{array}$ & $\begin{array}{c}\text { Không test } \\
\text { kích thích }\end{array}$ & Tổng số \\
\hline INH & $11(13,5 \%)$ & $70(86,5 \%)$ & $0(0 \%)$ & 81 \\
\hline RIF & $23(28,4 \%)$ & $58(71,6 \%)$ & $0(0 \%)$ & 81 \\
\hline ETH & $16(19,7 \%)$ & $64(79 \%)$ & $1(1,4 \%)$ & 81 \\
\hline PZA & $18(22,2 \%)$ & $61(75,3 \%)$ & $2(2,5 \%)$ & 81 \\
\hline Turbezid & $11(13,6 \%)$ & $7(8,6 \%)$ & $63(77,8 \%)$ & 81 \\
\hline Turbe & $1(1,2 \%)$ & $6(7,4 \%)$ & $74(91,4 \%)$ & 81 \\
\hline Tống & $\mathbf{8 0}$ & $\mathbf{2 6 6}$ & \multicolumn{2}{|c|}{$\mathbf{3 4 6}$ lần test } \\
\hline
\end{tabular}

Nhân xét: Trong 86 bệnh nhân, 81 bệnh nhân được test kích thích với cả thuốc đơn chất và thuốc kết hợp, 5 trường hợp còn lại do có phản ứng trên da ở mức độ 4 nên không có chỉ định test kích thích. Kết quả test kích thích với INH: dương tính 11 bệnh nhân chiếm 13,5\%, âm tính 70 bệnh nhân chiếm tỷ lệ $86,5 \%$. Kết quả test kích thích với RIF: dương tính 23 bệnh nhân 
chiếm 28,4\%, âm tính 58 bệnh nhân chiếm $71,6 \%$. Kết quả test kích thích EMB: dương tính 16 bệnh nhân chiếm 19,7\%, âm tính 64 bệnh nhân chiếm $79 \%$. Kết quả test kích thích PZA: dương tính 18 bệnh nhân tỷ lệ 22,2\%, âm tính 61 bệnh nhân chiếm 75,3\%. Kết quả test kích thích Tuberzid (RHZ): dương tính 11 bệnh nhân chiếm 13,6\%, âm tính 7 bệnh nhân chiếm 8,6\%. Kết quả test kích thích Tuber (RH): dương tính 1 bệnh nhân chiếm 1,2\%, âm tính 6 bệnh nhân chiếm 7,4\%. Như vậy trong các thuốc đơn chất, thuốc gây dị ứng nhiều nhất là RIF, tiếp theo là PZA, EMB và INH có tỉ lệ gây dị ứng thấp nhất. tính

Bảng 5: Kiêu hinh test kích thích dương

\begin{tabular}{|c|c|c|c|}
\hline \multicolumn{2}{|c|}{ Kiếu hình } & $\mathbf{n}$ & $\mathbf{\%}$ \\
\hline \multicolumn{2}{|c|}{ Dị ứng với 1 loại thuốc } & 54 & 80,6 \\
\hline $\begin{array}{c}\text { Dị ứng với } \\
\text { 2 loaai } \\
\text { thuốc }\end{array}$ & $\begin{array}{c}\text { Dị ứng RIF và } \\
\text { dị ứng INH }\end{array}$ & 4 & 5,9 \\
\cline { 2 - 4 } & $\begin{array}{c}\text { Dị ứng RIF và } \\
\text { dị ứng PZA }\end{array}$ & 3 & 4,8 \\
\hline
\end{tabular}

\begin{tabular}{|c|c|c|c|}
\hline \multirow{7}{*}{} & $\begin{array}{c}\text { Di ứng RIF và } \\
\text { dị ứng } \mathrm{ETH}\end{array}$ & 1 & 1,5 \\
\cline { 2 - 4 } & $\begin{array}{c}\text { Di ứng INH và } \\
\text { dị ứng PZA }\end{array}$ & 0 & 0 \\
\cline { 2 - 4 } & $\begin{array}{c}\text { Dị ứng INH và } \\
\text { dị ứng ETH }\end{array}$ & 2 & 3 \\
\cline { 2 - 4 } & $\begin{array}{c}\text { Di ứng PZA và } \\
\text { di ứng ETH }\end{array}$ & 3 & 4,8 \\
\hline Tống số & & $\mathbf{6 7}$ & $\mathbf{1 0 0}$ \\
\hline
\end{tabular}

Nhận xét: Trong tống số 67 bệnh nhân test kích thích dương tính có 54 bệnh nhân dương tính với 1 loai thuốc và 13 bênh nhân dương tính với 2 loại thuốc; không có bệnh nhân bị dị ứng với từ 3 thuốc chống lao trở lên. Trong 13 bệnh nhân test kích thích dương tính với 2 loại thuốc, có 4 bênh nhân test kích thích dương tính với $R$ và $H, 3$ bệnh nhân test kích thích dương tính với $R$ và $Z, 1$ bệnh nhân test kích thích dương tính với $R$ và $E, 2$ bênh nhân test kích thích dương tính với $H$ và $E, 3$ bệnh nhân test kích thích dương tính với $Z$ và $E$.

Bảng 6: Thời gian test kích thích dương tính

\begin{tabular}{|c|c|c|c|c|c|}
\hline $\begin{array}{c}\text { Loai thuốc } \\
\text { test kích } \\
\text { thích }\end{array}$ & $\begin{array}{c}\text { Test kích thích } \\
\text { dương tính } \\
\text { ngày 1 }\end{array}$ & $\begin{array}{c}\text { Test kích thích } \\
\text { dương tính } \\
\text { ngày 2 }\end{array}$ & $\begin{array}{c}\text { Test kích } \\
\text { thích dương } \\
\text { tính ngày 3 }\end{array}$ & $\begin{array}{c}\text { Test kích thích } \\
\text { dương tính } \\
\text { ngày 4 }\end{array}$ & $\begin{array}{c}\text { Tổng } \\
\text { số }\end{array}$ \\
\hline INH & $1(9 \%)$ & $5(45,5 \%)$ & $5(45,5 \%)$ & 0 & 11 \\
\hline RIF & $5(21,7 \%)$ & $12(52,2 \%)$ & $5(21,7 \%)$ & $1(4,4 \%)$ & 23 \\
\hline ETH & $7(43,7 \%)$ & $6(37,5 \%)$ & $3(18,7 \%)$ & 0 & 16 \\
\hline PZA & $2(11,2 \%)$ & $8(44,4 \%)$ & $8(44,4 \%)$ & 0 & 18 \\
\hline RHZ & $1(10 \%)$ & $4(40 \%)$ & $6(50 \%)$ & 0 & 11 \\
\hline RH & 0 & $1(100 \%)$ & 0 & 0 & 1 \\
\hline
\end{tabular}

Nhận xét: Bệnh nhân được test kích thích thường dương tính vào ngày thứ 2 hoặc ngày 3

Bảng 7: Mức độ dị ứng sau khi test kích thích

\begin{tabular}{|c|c|c|}
\hline $\begin{array}{c}\text { Mức độ dị } \\
\text { ứng }\end{array}$ & $\begin{array}{c}\text { Số lâan test kích } \\
\text { thích dương tính(n) }\end{array}$ & $\mathbf{\%}$ \\
\hline Mức độ 1 & 14 & 17,5 \\
\hline Mức độ 2 & 19 & 23,7 \\
\hline Mức độ̀ 3 & 46 & 57,5 \\
\hline Mức độ 4 & 1 & 1,3 \\
\hline Tống & 80 & 100 \\
\hline
\end{tabular}

Nhân xét: Tổn thương da mức đô 3 sau test kích thích chiếm tỉ lê cao nhất 57,5\%. 1 bênh nhân nào tổn thương da mức độ 4 sau test kích thích chiếm tỉ lệ 1,3\%.

\section{BÀN LUÂ̂N}

Trong nhóm nghiên cứu có $55,8 \%$ bệnh nhân biểu hiện mày đay, ban, chấm; $98,8 \%$ biểu hiện ngứa trên da. Nghiên cứu của chúng tôi có sự khác biệt với nghiên cứu của Bùi Văn Dân (2013), 100\% bệnh nhân biểu hiện mày đay, $100 \%$ bệnh nhân biểu hiên ngứa trền da. Thuốc khi đưa vào trong cơ thể được sự nhận biết và sinh ra đáp ứng miễn dịch, thời gian cho quá trình này khác nhau tùy theo mối thuốc. Tuy nhiên thời gian xuất hiện $A D R$ thuốc chống lao chậm hơn so với các thuốc khác. Nghiên cứu số liệu bệnh nhân trong vòng 1 năm, Gholami (2006) cho thấy thời gian xuất hiện ADR từ khi dùng thuốc dao động từ 1-30 ngày và không có trường hợp nào xuất hiện $A D R$ ngay trong ngày đầu tiên. $A D R$ chủ yếu xảy ra trong khoảng thời gian 10 ngày sau dùng thuốc chiếm $71,6 \%$. Theo nghiên cứu của chúng tôi: $9 \%$ số trường hợp xuất hiện ngay trong giờ đầu dùng thuốc, 40\% xuất hiện dị ứng trong khoảng thời gian 1$24 \mathrm{~h}, 51 \%$ xuất hiện từ 1 ngày - nhiều tuần. Sự khác biệt giữa nghiên cứu của chúng tôi và nghiên cứu của Gholami do tiêu chuẩn lựa chọn bệnh nhân nghiên cứu. Theo tác giả Nguyễn Vằn Đoàn (2005) khi nghiên cứu về dị ứng thuốc chống lao ở 64 BN cho thây hầu hết các phản ứng dị ứng do thuốc chống lao thường xảy ra sau 24 giờ chiếm $85,71 \%$. Kết quả này cũng phù 
hợp do tác giả lựa chọn tất cả các trường hợp dị ứng thuốc chống lao bao gồm cả các trường hợp quá mẫn muộn.

Nguyên nhân kháng thuốc có thể kể đến do trong quá trình điều trị bệnh nhân xảy ra $A D R$ và phải ngừng thuốc. Thời gian ngừng thuốc khác nhau tùy mức độ trầm trọng của $A D R$. Trong nhóm nghiên cứu, qua sơ bộ đánh giá thời gian ngừng thuốc trung bình 4,3 ngày, bệnh nhân ngừng thuốc ít nhất 1 ngày, nhiều nhất 16 ngày. Kết quả nghiên cứu của chúng tôi so với kết quả nghiên cứu của tác giả Breen (2006) cho thây thời gian ngừng thuốc của chúng tôi ngắn hơn. Theo tác giả này, thời gian ngừng thuốc chống lao trung bình khoảng 3 tuần và bệnh nhân ngừng thuốc ít nhất cũng khoảng 1 tuần. Tổn thương da dạng mày đay là tổn thương da nhe, điêuu trị đáp ứng tốt với các thuốc kháng histamin và corticoid do đó có thể rút ngắn khoảng thời gian ngừng thuốc trong nhóm nghiên cứu. Trong 86 bênh nhân nghiên cứu có dị ứng trên da, có $44,2 \%$ bệnh nhân được sử dụng thuốc kháng histamin, 33,7\% bệnh nhân được sử dụng thuốc kháng histamin kèm corticoid. Trong nghiên cứu về ADR khi sử dung thuốc chống lao Gholami (2006) kết quả 34,5\% trường hợp khi xảy ra ADR, thái độ của bác sĩ điều trị ngừng thuốc và $21 \%$ trường hợp tiếp tục dùng thuốc chống lao kèm theo các thuốc điều trị triệu chứng.

Trong 86 bệnh nhân có dị ứng trên da, 5 bệnh nhân có mức độ 4 tổn thương trên da nên không thực hiện test kích thích, 81 bênh nhân được thực hiện test kích thích. Test kích thích được coi là tiêu chuẩn vàng trong chẩn đoán nguyên nhân dị ứng thuốc. Trong nghiên cứu tiến hành trên 898 bênh nhân, 1372 test kích thích đã được thực hiện, Messaad (2004) báo cáo test kích thích cho kết quả dương tính trong $17,6 \%$ số test kích thích đã thực hiện. Kết quả này phù hợp với kết quả nghiên cứu của chúng tôi. Trong nhóm bệnh nhân nghiên cứu 346 lượt thuốc đã được chỉ định thực hiện test kích thích, 266 test cho kết quả âm tính chiếm 76,9\%; 80 test cho kết quả dương tính chiếm 23,1\%. Tuy nhiên khi đánh giá bệnh nhân dương tính khi thực hiện test kích thích với thuốc chống lao hỗn hợp là thấp hơn. Điều đó có thể được lý giải do sự phối hợp thuốc trong điều trị bệnh dẩn đến một bệnh nhân được chỉ định test kích thích nên số lượng test kích thích dương tính/bệnh nhân lớn hơn nhiều so với số test kích thích dương tính/số lượt thuốc thực hiên test kích thích. Kết quả này cùng phù hợp với kết quả nghiên cứu được thực hiện bởi Lehloenya (2011) khi thực hiện test kích thích lại với các thuốc điều trị lao cho 46 bệnh nhân ADR có biểu hiện da, trong đó $50 \%$ số bệnh nhân cho kết quả dương tính.

Phác đồ điều trị bệnh lao gồm nhiều thuốc phối hợp do đó khi xảy ra phản ứng dị ứng rất khó khăn trong chẩn đoán thuốc gây ra phản ứng. Tuy nhiên khi thực hiện test kích thích, lần lượt từng thuốc được tiến hành do đó có thể xác định nguyên nhân gây dị ứng một cách chính xác. Số liệu báo cáo do Daniel Vervloet (1992) và cộng sự cho thây tần suất xuất hiện $A D R$ ở các thuốc điều trị lao khác nhau. Tần suất ADR nói chung khi sử dụng INH khoảng 0,49/100 BN điêu trị/tháng, phản ứng dị ứng xảy ra khi sử dụng INH khoảng $5 \% \mathrm{BN}$, tổn thương da do thuốc $2 \%$. Tần suất ADR khi sử dụng RIF $0,43 / 100 \mathrm{BN}$ điều trị/tháng, tổn thương da nhe gặp khoảng từ 0,5-5\%, ADR khi điêuu trị với PZA dao dộng từ 1,31-1,61/BN điều trị/tháng, $A D R$ trong nhóm $B N$ sử dụng $E M B$ chiếm 0,07/100 BN điêu trị/tháng, dị ứng STREP gặp khoảng trên 2\% số trường hợp. Trong 81 bệnh nhân được thực hiên test kích thích trong nghiên cứu, tỉ lệ test kích thích dương tính ở các thuốc lần lượt là $\operatorname{RIF}(28,4 \%)>\operatorname{PZA}(22,2 \%)>\mathrm{EMB}(19,7 \%)>\mathrm{INH}$ $(13,5 \%), \mathrm{RHZ}(1363 \%)>\mathrm{RH}(1,2 \%)$. Phân loại theo thứ tự này cũng gần giống với kết quả do tác giả Nguyễn Văn Đoàn (2005) báo cáo về các thuốc chống lao gây dị ứng trong nhóm bệnh nhân điều trị lao. Có sự khác biệt với kết quả nghiên cứu của tác giả Lehloenya khi nghiên cứu trên 298 bệnh nhân đã xảy ra ADR ở 65 trường hợp. Trong số đó có 46 bệnh nhân được thực hiện test kích thích. Trong các trường hợp bệnh nhân thực hiện test kích thích thì RIF là thuốc gặp nhiều nhất 13/23 (57\%), INH là 5/23(22\%), PZA là $3 / 23(13 \%)$, và $E M B$. Có thể nhận thây RIF có khả năng gây dị ứng cao nhất so với các thuốc còn lại. RIF là thuốc có vai trò quan trọng nhất trong điều tri bênh lao do tác dung diệt khuẩn và kìm khuẩn. Tuy nhiên với kết quả như vậy, theo chúng tôi đây là một trong những khó khăn khi điêu trị bệnh lao đối với nhân viên y tế và bênh nhân, dẫn tới việc bênh nhân bỏ điều trị, hoặc phải đổi phác đồ điều trị ở những cơ sở chưa có kinh nghiệm giảm mấn cảm. Điều đáng chú ý trong nghiên cứu của chúng tôi, có tỉ lệ không nhỏ bệnh nhân bị dị ứng với 2 loại thuốc chống lao (13 trường hợp), trong đó đặc biệt lưu ý tới 4 bệnh nhân bị dị ứng với cả RIF và INH.

Về mức độ di ứng trên da sau khi test kích thích (Bảng 7), kết quả này có sự khác biệt so với tổn thương da ban đầu khi bệnh nhân xuất 
hiện di ứng. Trong 86 bệnh nhân có biểu hiên di ứng trên da, tổn thương da mức độ 2 có 47 bệnh nhân chiếm tỉ lệ cao nhất $55 \%$, mức độ 3 $39 \%$ và mức độ 4 chiếm tỉ lê thấp nhất $6 \%$. Không có bệnh nhân tổn thương da mức độ 1 . Những bệnh nhân khi dị ứng phải nhập viện thường biểu hiện thời gian dài, mức độ nặng nển không có trường hợp nào tổn thương da mức độ 1. Khi thực hiện test kích thích, những trường hợp dị ứng trên da mức độ 4 đã được loại trừ, không thực hiện test kích thích nên tỉ lệ tổn thương da mức đô 4 sau test kích thích chiếm tỉ lệ thấp 1,3\%.

\section{KẾT LUÂNN}

Phác đồ điều trị bệnh lao gồm nhiều thuốc phối hợp do đó khi xảy ra phản ứng dị ứng rất khó khăn trong chẩn đoán thuốc gây ra phản ứng. Tuy nhiên khi thực hiện test kích thích, lần lượt từng thuốc được tiến hành do đó có thể xác định nguyên nhân gây dị ứng một cách chính xác. Các thuốc dị ứng có tỉ lệ từ cao đến thấp lần lượt RIF, PZA, EMB, INH. Thời gian test kích thích dương tính chủ yếu vào ngày thử 2 và 3

TÀI LIÊU THAM KHẢO

1. Nguyễn Văn Đoàn (2009), Dị ứng thuốc, Nhà xuất bản $Y$ hoc

2. Nguyển Văn Đoàn (2005). Nghiên cứu dị ứng thuốc chống lao trên bênh nhân lao điêuu tri nội trú tại viện lao và bệnh phổi trung ương. Tạp chí nghiên cứu y hoc, 4, 52-57

3. Nguyễn Viết Nhung và Nguyễn Trọng Thông (2016). Phát hiện, đánh giá, xử trí tác dụng không mong muốn của thuốc chống lao. Cẩm nang hướng dâ̂n sử dụng thuốc điều trị lao. nhà xuất bản Thanh niên, Hà Nối.

4. Bộ Y tế (2018). Quyết định về việc ban hành hướng dẫn chân đoán, điêu trị và dư phòng bênh lao

5. Gholami K., Kamali E., Hajiabdolbaghi M. và cộng sứ. (2006). Evaluation of anti-tuberculosis induced adverse reactions in hospitalized patients. Pharm Pract (Granada), 4(3), 134-138

6. Siripassorn K., Ruxrungtham K., và Manosuthi W. (2018). Successful drug desensitization in patients with delayed-type allergic reactions to anti-tuberculosis drugs. Int $]$ Infect Dis, 68, 61-68

\section{VAI TRÒ CỦA CHỤP CộNG HƯởNG TỪ TRONG CHẨN ĐOÁN U BUỒNG TRỨNG CHƯA PHÂN ĐİNH LÀNH TÍNH VÀ ÁC TÍNH THEO SIÊU ÂM}

Lê Triệu Hải1, Bùi Văn Hoàng² , Võ Minh Tuấn', Huỳnh Phượng Hải1, Tô Mai Xuân Hồng ${ }^{1}$, Nguyễn Thị Minh Trang ${ }^{1}$

\section{TÓM TẮT}

Đặt vấn đề: Việc chẩn đoán u buồng trứng (UBT) chưa phân định lành tính và ác tính theo siêu âm vẫn là thách thức trong thực hành lâm sàng. Việc phát hiên sớm và phân nhóm chẩn đoán đúng giúp đánh giá chính xác và định hướng chiến lược điêuu trị phù hợp. Mục tiêu: Xác định giá trị chẩn đoán của cộng hưởng từ $(\mathrm{CHT})$ trong chẩn đoán ung thư buồng trứng (UTBT) ở những trường hợp không phân định được lành tính và ác tính trên siêu âm theo qui tắc đơn giản Nhóm phân tích hệ thống các UBT quốc tế - IOTA tại Bênh viên Từ Dũ. Phương pháp: Thiết kế nghiên cứu: xét nghiệm chẩn đoán, hối cứu. Nghiên cứu được thực hiên bằng viêc truy xuất hình ảnh chup $\mathrm{CHT}$ vùng bụng chậu của 1116 phụ nữ được chẩn đoán u phần phụ thực hiên tại Bệnh viện Từ Dũ từ ngày 01/01/2019 đến ngày $31 / 03 / 2020$. Phân lập nhóm bệnh nhân đã được chụp $\mathrm{CHT}$ nhằm xác định đặc điểm của các khối u phần phụ mà siêu âm không thể

${ }^{1}$ Đại học Y Dược TP. Hồ Chí Minh

Bềnh viện Tữ Dũ

Chịu trách nhiệm chính: Võ Minh Tuấn

Email: vominhtuan@ump.edu.vn

Ngày nhận bài: 20.4.2021

Ngày phản biên khoa hoc: 24.5.2021

Ngày duyệt bài: 15.6.2021 phân đinh lành tính và ác tính theo siêu âm. Giải phẫu bệnh (GPB) được xem là tiêu chẩn vàng để xác định đồ chính xác của của CHT. Kết quả: Với tổng số 246 bệnh nhân có khối u phần phụ được chụp CHT, kết quả mô tả đúng $83 \%$ các khổi u phần phu, với độ chính xác chung tính cho chẩn đoán UTBT là $83,9 \%$. Trong tiên đoán UTBT, độ nhạy của chụp CHT $84 \%$ (KTC 95\% 75-91); giá trị tiên đoán dương là 70\% (KTC 95\% 60 - 78); và giá trị tiên đoán âm là 92\%. CHT với các hình ảnh như nhú thành nang $(O R=8,6)$, bắt thuốc không đồng nhất $(\mathrm{OR}=8,3)$, dịch ổ bụng $(\mathrm{OR}=15,4)$ có giá trị dự đoán ác tính tốt nhất. Kết luận: CHT có độ chính xác cao trong chẩn đoán UBT. Nên triển khai việc áp dụng chụp $\mathrm{CHT}$ cho những phụ nữ chưa xác định được UBT lành tính và ác tính theo siêu âm.

Tư khóa: giá trị chẩn đoán; chụp cộng hưởng từ, ung thư buồng trứng.

\section{SUMMARY}

THE ROLE OF MAGNETIC RESONANCE IMAGING IN THE DIAGNOSIS OF ADNEXAL MASSES IN BORDERLINE OF FROM BENIGN AND MALIGNACY

Background: Ovarian tumors in borderline of benign and malignancy are a major challenge to clinical practices. Early detection and precise diagnosis 